\title{
Relato de um caso de melanoma de conjuntiva
}

\author{
Conjuntival melanoma: a case report
}

\author{
Carlos Gustavo Leite Vieira ${ }^{(1)}$ \\ Célio Sérg'io Guimarães ${ }^{(2)}$ \\ Cristiana Pace Silva de Assis ${ }^{(1)}$ \\ João Agostini Netto ${ }^{(3)}$
}

\begin{tabular}{|c|}
\hline RESUMO \\
\hline Objetivo: Relatar um caso raro de melanoma de conjuntiva de \\
longa evolução em paciente melanodérmica. \\
Método: Análise de caso. \\
Resultado: Até a presente data a paciente encontra-se bem sem \\
evidências de recorrência da patologia em questão após excisão local. \\
Conclusão: Observamos que mesmo sem a realização de crioterapia \\
adjuvante ou medidas mais agressivas, existem alguns casos como esse \\
que acabamos de relatar para o qual a excisão simples pode garantir a \\
cura. Um aspecto importante deste relato é a importância do exame \\
histopatológico de peças e fragmentos cirúrgicos removidos.
\end{tabular}

Palavras-chave: Melanoma; Conjuntiva.

\section{INTRODUÇÃO}

Melanoma de conjuntiva é um tumor que pode acometer a mucosa dos olhos e das pálpebras. O tumor incide tipicamente na quinta década de vida. É raro o acometimento em negros ou durante as primeiras décadas de vida. A exposição a radiação ultra violeta parece estar associada há uma maior incidência desse tumor. A história natural dessa patologia ainda não está bem esclarecida. Segundo alguns autores certos melanomas apresentam-se como simples nódulos pigmentados que nunca sofreram recorrência após uma excisão local, outros são mais agressivos ou recorrem de tempos em tempos ${ }^{1}$. Melanomas malignos primários são tumores raros, constituindo apenas $2 \%$ dos tumores malignos oculares ${ }^{2}$. Essa escassez em casos é a grande responsável pelo fato de que muito de que se tem escrito a respeito dessas lesões pigmentadas na conjuntiva são muitas vezes controversas ou especulativas. A natureza controversa deve-se às diferentes classificações das lesões, dos diferentes modos de tratamento e da incerteza dos oftalmologistas quanto a melhor conduta a ser adotada ${ }^{3}$. O melanoma é um tumor maligno que resulta da transformação de melanócitos e nevus. Podendo ser pigmentado e não pigmentado. Apresenta três forma clínicas:

1) Melanoma com melanose primária adquirida: ocorre quando o tumor evolui indiretamente após um variável e prolongado curso de melanose primária adquirida. Nesses casos a principal suspeita de malignidade devese ao aparecimento repentino de um ou mais nódulos em outros planos de lesão, podendo ou não acometer a pele adjacente;

2) Melanoma primário sem melanose primária adquirida;

3) Melanoma derivado de um nevus pré existente sendo esse muito raro.

A taxa geral de mortalidade oscila em torno de $25 \%$. Tumores originados da conjuntiva bulbar tem um prognóstico excelente com sobrevida em cinco anos próxima de $100 \%$. 
A taxa de sobrevida em 5 anos para os tumores originados do limbo é de $80 \%$ e para os originados na conjuntiva palpebral é de $50 \%$. O prognóstico desfavorável nesse último caso pode ser explicado pela lentidão diagnóstica.

\section{DESCRIĈ̃O DO CASO}

I. D:M.J., 73 anos, melanoderma, sexo feminino, casada, natural e residente em Rio Espera/MG.

H.M.A: Paciente procurou o serviço em 09/98 queixando-se de nódulo pigmentado e dor no olho direito. Relatando o aparecimento dessa lesão há quinze anos. Durante todo esse período nunca procurou um oftalmologista apesar de relatar um aumento indolor da lesão. Negando dor até há uma semana. Sem história de patologias oculares ou traumas prévios.

Acuidade visual:

OD:20/40 sc $(0,5)$

OE:20/40 sc $(0,5)$

Tonometria de aplanação (10:00h):

OD: $14 \mathrm{mmHg}$

$\mathrm{OE}: 14 \mathrm{mmHg}$

À Biomicroscopia:

OD: apresentou além da lesão nodular, entrópio e ceratite (sendo essa última o que motivou a consulta).

OE: encontrava-se calmo, sem alterações

Ao exame de fundo de olho não apresentou nenhuma alteração em $\mathrm{AO}$.

Em 09/98 a paciente retorna para controle com melhora da ceratite no OD. Nessa mesma data foi marcada a cirurgia questionando se tratar de um nevus e para tanto pedido o risco cirúrgico. Em 01/99 foi realizada a excisão local de um nódulo conjuntival com enxerto de mucosa oral no local. Não foi aplicada crioterapia, pois com quinze anos de evolução todos acreditavam tratar-se de um nevus. Para a surpresa de todos ao chegar o resultado anatomo-patológico foi evidenciado uma lesão neoplásica constituída de células atípicas, de núcleos hipertróficos, hipercromasia e contornos irregulares, típicos de melanoma maligno (Tabela 1). Foi pedido revisão de lâmina que confirmou o diagnóstico (Fig. 1 e 2).

Na avaliação pós operatória e no acompanhamento clínico da paciente não foi evidenciada metastases conforme comprovação pelos exames de controle de cura, sendo eles: RX de

Tabela 1. Anátomo-patológico

\section{MACROSCOPIA}

Material recebido em frasco rotulado e constituído por porção irregular de tecido pardo-escuro medindo $2,7 \times 1,7 \times 1,0 \mathrm{~cm}$.

Superfície de corte enegrecida e homogênea.

\section{MICROSCOPIA}

Cortes histológicos do material evidenciam lesão neoplásica constituída por células atípicas, de núcleos hipertróficos, nucléolos evidentes, ou com hipercromasia e contornos irregulares. O citoplasma é eosinofílico ou claro contendo melanina. CONCLUSÃO: Melanoma

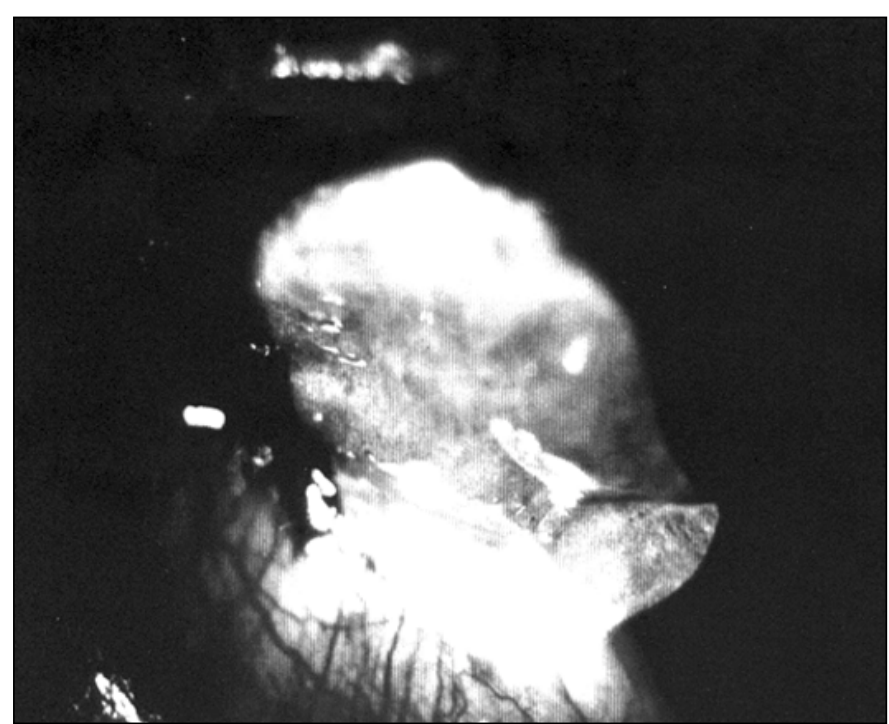

Fig. 1 - Aspecto clínico da lesão mostrando-se como uma massa sólida, nodular, imóvel, medindo $2,7 \times 1,7 \times 1,0 \mathrm{~cm}$, acometendo a conjuntiva bulbar e tarsal inferior.

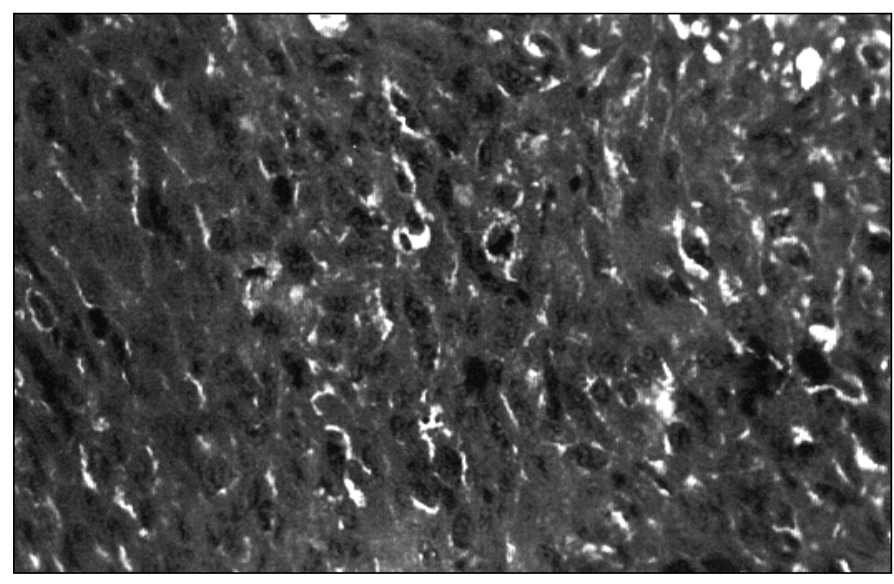

Fig. 2 - Aspecto histopatológico da lesão, mostrando células atípicas, de núcleos hipertróficos, hipercromáticos, de contornos irregulares. O citoplasma é eosinofílico ou claro contendo melanina.

tórax, T.C. de órbita (Fig.3) e provas de função hepática, todos dentro da normalidade.(pesquisa de metastases hepáticas e pulmonares) (Tabela.2). Até o presente momento a paciente encontra-se bem, sem evidências de lesões sugestivas de metástases em atividade.

\section{MATERIAL E MÉTODOS}

Foi estudada em nosso serviço uma paciente de 73 anos admitida com um nódulo em conjuntiva bulbar e tarsal inferior do olho direito. O método utilizado fora o da análise do caso.

\section{RESULTADO}

Até a presente data a paciente estudada encontra-se bem 


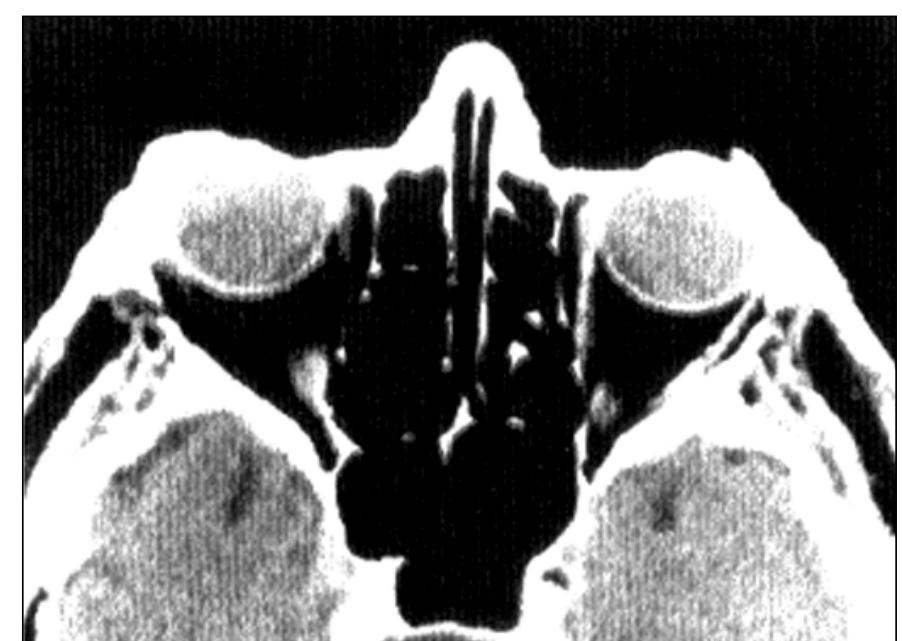

Fig. 3 - Tomografia computadorizada mostrando a não invasão da lesão para dentro do olho, órbita ou cérebro.

\section{Tabela 2. Exames Laboratoriais}

Bilirrubina Total: $0,60 \mathrm{mg} / \mathrm{dl}$

Bilirrubina Direta: $0,10 \mathrm{mg} / \mathrm{dl}$

Fosfatase Alcalina: 176,0 U/L

Gama-Glutamil Transferase: 21,0 U/L

Aspartato Aminotransferase: $21,0 \mathrm{U} / \mathrm{L}$

Alamina Aminotransferase: $8,0 \mathrm{U} / \mathrm{L}$

Tempo de Coagulação: 10,00 minutos

Tempo de Sangramento: 1,00 minuto

Tempo de Protrombina: 13,80 segundos

Tempo de Tromboplastina parcial ativada: 39,00 segundos

Contagem de Plaquetas: $200,00 \mathrm{mil} / \mathrm{mm}$

Atividade de Protrombina: $71,0 \%$

sem evidência de recorrência da patologia em questão. Observamos que de fato, mesmo sem a realização de uma crioterapia adjuvante no tratamento de melanoma de conjuntiva, existem alguns casos como esse que acabamos de relatar, que a excisão simples garante a cura.

\section{DISCUSSÃO}

Em relação ao tratamento, existem várias técnicas e variáveis prognósticos. Dentre as mais utilizadas temos: excisão local em geral associada à crioterapia ou laser local; exentereção reservada aos grandes tumores disseminados para a pálpebra e a órbita; e quimioterapia paliativa para a doença metastática. No caso relatado em função do tempo de evolução da patologia, cor e idade avançada da paciente, foi realizada exérese da lesão e enxerto local em função da hipótese de nevus ter sido a mais cogitada. Após o resultado do anátomopatológico optamos pelo seguimento clínico do caso. Outros dados que favoreceram a conduta conservadora foi a acuidade visual preservada no olho acometido e a incerteza de benefícios com condutas agressivas após o tratamento já realizado. A referida paciente vêm fazendo controle mensal com exame oftalmológico completo e exames complementares sem evidências de recidiva local ou doença metastática. Atualmente, aos exames trimestrais vêm mantendo acuidade visual, ausência de alterações locais e fundoscópicas. O serviço de oncologia têm realizado trimestralmente o acompanhamento clínico do caso estando a paciente mantendo provas de função hepática e RX de tórax dentro dos limites da normalidade. $\mathrm{O}$ presente relato é interessante sobretudo para mostrar a importância do exame histopatológico das peças e fragmentos cirúrgicos removidos.

\section{SUMMARY}

Purpose: The authors describe a rare case of malignant conjunctival melanoma with a long evolution.

Methods: A case report.

Results: Until this time the patient does not show any sign of relapse of this melanoma, after local excision.

Conclusion: Without cryotherapy or more agressive methods we observe that there are some cases of conjunctival melanoma that might be cured with only a local excision. An important aspect of this case is the relevance of the histopathologic analysis of the removed surgical fragments.

\section{Keywords: Melanoma; Conjunctiva.}

\section{REFERÊNCIAS BIBLIOGRÁFICAS}

1. Shields J. Diagnosis and management of orbital tumors. WB Saunders Company, 1989:

2. Paridaens ADA, Minassian DC, Mc Cartney ACE, Hungerford JL. Prognostic factors in primary malignant melanoma of the conjunctiva:a clinicopathological study of 256 cases. Brit J Ophthalmol 1994;78:252-9.

3. Singh J, Sioulis C, Cullens JF. Conjunctival Melanoma. Arch Ophthalmol 1996;114:1528-9.

4. Sergard S. Cell proliferation as a prognostic indicator in conjuntival malignant melanoma. Amer J Ophthalmol 1993;116:93-7.

5. Lommatzsch PK, Lommatzsch RE, Kirsch I, Fuhrmann P. Therapeutic outcome of patients suffering from malignant of the conjunctiva. Br J Ophthalmol 1990;74:615-9.

6. Baddini-Caramelli C. Tumores oculares: Fatores que contribuem para o atraso do atendimento oftalmológico. Arq Bras Oftalmol 1996;59(4):54.

7. Rocha A. Incidência de neoplasia conjuntival no estado do Amazonas/Brasil. Arq Bras Oftalmol 1997;60(4):59.

8. Hicks C, Liu C, Hiranandani M, Garner A, Hungerford J. Conjunctival melanoma after excision of a lentigo maligna melanoma in the ipsilateral eyelid skin. Br J Ophthalmol 1994;78:317-8. 